\title{
A RELAÇÃO ENTRE A EDUCAÇÃO PROFISSIONAL E A EDUCAÇÃO BÁSICA NA CONAE 2010: POSSIBILIDADES E LIMITES PARA A CONSTRUÇÃO DO NOVO PLANO NACIONAL DE EDUCAÇÃO
}

\author{
Dante Henrique Moura*
}

\begin{abstract}
RESUMO: O texto discute a relação entre a educação profissional (EP) e a educação básica (EB), especialmente o ensino médio (EM), assumindo como pressuposto a educação como direito igualitário de todos, tendo em vista a elaboração do novo Plano Nacional de Educação (PNE) a partir da Conferência Nacional de Educação (CONAE 2010). Faz-se uma síntese histórica da relação entre EB e EP, considerando a dualidade estrutural e a funcionalidade da educação ao modelo de desenvolvimento econômico. Propóe-se, com base nos princípios da politecnia, a integração entre elas como forma de contribuir para o rompimento dessa dualidade estrutural. Analisa-se o conteúdo do Documento Final da CONAE no que se refere à relação entre EP e EM, comparando-o com os princípios do EM integrado.
\end{abstract}

Palavras-chave: Educação básica. Educação profissional. Ensino médio. Integração. Plano Nacional de Educação.

THE RELATION BETWEEN VOCATIONAL EDUCATION AND BASIC EDUCATION IN 2010 CONAE: POSSIBILITIES AND LIMITS TO CONSTRUCT THE NEW NATIONAL PLAN FOR EDUCATION

ABSTRACT: This paper discusses the relation between vocational education (VE) and basic education (BE), especially in high school (HS). It assumes education is an egalitarian right and reflects on the new National Plan for Education, which will be drawn from the last National Conference on Education (2010 CONAE). It presents

Doutor em Educação e professor do Instituto Federal de Educação, Ciência e Tecnologia do Rio Grande do Norte (IFRN).E-mail: dante@cefetrn.br 
a historic summary of the relation between $\mathrm{VE}$ and BE taking into account the structural duality and the functionality of education within the economic development model. Based on the principles of technological education, it proposes to integrate both as a way to help breach such structural duality. It analyses the content of CONAE's final resolution regarding the relation between VE and HS and compares it to the principles of technological education.

Key words: Basic education. Vocational education. High school. Integration. National Plan for Education.

\section{Introdução}

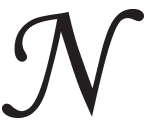

este texto, discute-se a relação entre a educação profissional (EP) e a educação básica (EB), especialmente o ensino médio (EM), adotando como pressuposto a educação como direito igualitário de todos os adolescentes, jovens e adultos, tendo em vista a elaboração do novo Plano Nacional de Educação (PNE) a partir da Conferência Nacional de Educação (CONAE 2010).

O texto faz uma breve recuperação histórica da relação entre EB e EP do Brasil colonial aos dias atuais, tendo como categorias de análise norteadoras a dualidade estrutural entre ambas e a funcionalidade da educação ao modelo de desenvolvimento econômico. Em seguida, discute-se a relação entre EP e EM nos anos 2000 e suas perspectivas no âmbito do novo PNE, considerando a produção acadêmica, os principais acontecimentos e os documentos oficiais, particularmente, o Documento Final da CONAE, realizada em 2010 a partir das Conferências Intermunicipais e Estaduais de Educação ocorridas no segundo semestre de 2009.

Educação básica e educação profissional: dualidade histórica e funcionalidade aos determinantes econômicos

No Brasil, a educação, historicamente, tem sido funcional ao modelo de desenvolvimento econômico, fundamentado, na fase colonial, na exploração e expropriação de matéria-prima destinada às metrópoles europeias. Nesses primeiros séculos, tal modo de produção não exigia pessoal qualificado, de forma que não havia grandes preocupações com a educação das classes trabalhadoras, em função das tarefas que lhes cabiam. 
Os primeiros indícios da EP, como compreendida hoje, são do início do século XIX, quando se criou o Colégio das Fábricas. Ainda naquele século, foram criadas outras sociedades civis destinadas a dar amparo a crianças órfãs e abandonadas, possibilitando-lhes instrução teórico-prática e iniciando-as no ensino industrial. Portanto, a EP origina-se predominantemente na sociedade civil e com objetivos assistencialistas.

$\mathrm{Na}$ transição entre os séculos XIX e XX, começa um esforço público de organização da formação profissional, mesclando ao viés assistencialista a preparação de operários para o incipiente processo de industrialização.

Em 1909, Nilo Peçanha criou as Escolas de Aprendizes Artífices destinadas aos pobres e humildes -, distribuindo-as em todo o país. Paralelamente, organizou-se o ensino agrícola para capacitar chefes de cultura, administradores e capatazes, o que evidenciou um redirecionamento da EP, ampliando-se seu horizonte de atuação para atender aos interesses econômicos emergentes nos campos da agricultura e da indústria.

Em 1930, cria-se o Ministério da Educação e Saúde Pública. Também foi dessa década o Manifesto dos Pioneiros da Educação Nova, que assumia a perspectiva de uma escola democrática e se propunha a proporcionar oportunidades para todos. Entretanto, idealizava a educação em duas grandes categorias: atividades de humanidades e ciências (de natureza mais intelectual) e cursos de caráter técnico (de natureza mecânica e manual), ratificando-se a distinção entre os que pensam e os que executam.

No início dos anos de 1940, foram promulgadas as Leis Orgânicas da Educação Nacional (ou Reforma Capanema) para organizar a EB coerentemente com as necessidades da emergente indústria nacional, baseada no modelo de substituição de importações.

A reforma conferia importância estratégica ao sistema educacional, mas também reafirmava a sua dualidade, pois o acesso ao ES continuava sendo em função dos conteúdos gerais das letras, ciências e humanidades, únicos considerados válidos para a formação da classe dirigente (Kuenzer, 1997).

No final dos anos de 1940, inicia-se um período de redemocratização pós-Estado novo, muito rico em embates em torno de diferentes projetos de sociedade. Dessa forma, a gênese da primeira Lei de Diretrizes e Bases da Educação Nacional (LDB) - Lei n. 4.024/1961) - 
A relação entre a educação profissional e a educação básica na CONAE $2010 \ldots$

ocorre em meio a polarizaçóes. Os setores populares e populistas pleiteavam, entre outros aspectos, a extensão da rede escolar gratuita e a equivalência entre o colegial e o profissionalizante, com possibilidade de transferência de um para outro (Freitag, 2000).

Já os setores vinculados às classes hegemônicas reivindicavam a redução da ação da sociedade política sobre a escola, defendendo que a educação fosse ministrada predominantemente em escolas privadas.

A primeira LDB reflete tais contradiçōes, mas, pela primeira vez, um regulamento envolve todos os níveis e modalidades de ensino e dá plena equivalência entre os cursos acadêmicos e profissionalizantes de mesmo nível, sem necessidade de adaptação, colocando fim, legalmente, à dualidade no ensino. Entretanto, na prática, ela permaneceu. Os currículos se encarregaram de mantê-la, pois a vertente propedêutica continua privilegiando os conteúdos exigidos no acesso ao ES e, nos cursos profissionalizantes, os conteúdos são vinculados às necessidades imediatas dos setores produtivos. Por outro lado, a LDB proporciona a liberdade de atuação da iniciativa privada na educação e até promove incentivos e isenções.

A fase inicial da primeira LDB é marcada pelo golpe de 1964. Em 1971, há a reforma da EB por meio da Lei n. 5.692/1971 que, entre outros aspectos, institui a profissionalização obrigatória no $2^{\circ}$ grau (atual EM), fruto de uma conjugação de fatores. Por um lado, era crescente a demanda das classes populares por acesso a níveis mais elevados de escolarização, acarretando pressão pelo aumento de vagas no ES. Por outro lado, o governo tinha o projeto de desenvolvimento nacional calcado em uma nova fase de industrialização, conhecida como o "milagre brasileiro", que demandava por técnicos de nível médio qualificados para atender a tal crescimento.

Assim, o governo optou por dar resposta diferente às demandas educacionais das classes populares, mas que pudesse convencê-las. Utilizou-se, então, a via da profissionalização no $2^{\circ}$ grau, o que, supostamente, garantiria a inserção no mercado de trabalho.

Ao tornar compulsória a profissionalização do $2^{\circ}$ grau, a reforma, do ponto de vista legal, eliminaria a dualidade entre educação geral e formação profissional. Entretanto, o que ocorreu foi algo bem distinto. Nas redes estaduais, a profissionalização não se implantou completamente. Em primeiro lugar, a concepção curricular empobrecia a formação 
geral em favor de uma profissionalização instrumental para o mercado de trabalho. Com isso, apesar de se alegar a importância da relação entre teoria e prática para a formação integral do cidadão, ao invés de se ampliar a duração do $2^{\circ}$ grau para nele incluir os conteúdos da EP de forma integrada à educação geral, reduziram-se os últimos em favor dos primeiros. Estes assumiram um caráter instrumental, pois não havia a base científica que permitisse caminhar na direção de conhecimentos mais complexos inerentes ao mundo do trabalho.

Além disso, a falta de adequado financiamento e de formação de professores comprometeu a qualidade dos cursos nas redes públicas estaduais. Paralelamente, nas escolas técnicas e agrotécnicas federais (ETF e EAF), origem dos atuais Institutos Federais, a realidade foi diferente. Essas escolas se consolidaram, respectivamente, nas vertentes industrial e agropecuária, por meio de cursos demandados pelo modelo de desenvolvimento econômico. Isso ocorreu, entre outros aspectos, porque na rede federal existiu o que faltou às estaduais: financiamento adequado e corpo docente especializado.

Por outro lado, a reforma foi "simplesmente descartada (com raras exceções) pela rede privada devido ao seu elevado custo" (Germano, 2005 , p. 187). Diante desse quadro, observa-se um acentuado movimento da classe média das escolas públicas para as privadas, buscando a garantia de uma formação que permitisse aos seus filhos continuar os estudos no Es. Gerou-se um ciclo negativo, ainda não interrompido, de deterioração da escola básica pública brasileira, o qual reforça a dualidade entre EB e EP, entre educação pública e privada, e fortalece as empresas privadas do setor educacional (Germano, 2005).

A não implantação plena da reforma resultou em sua gradual flexibilização e diminuição da oferta. Assim, no final dos anos de 1980, em meio ao trâmite que resultou na segunda LDB (Lei n. 9.394/96), já quase não havia mais $2^{\circ}$ grau profissionalizante, exceto nas ETF, EAF e em poucas redes estaduais. Durante esse processo, o país novamente saía de um período ditatorial e tentava reconstruir o Estado de direito, de modo que os conflitos eram intensos em torno de projetos societários distintos.

$\mathrm{Na}$ esfera educacional, a principal polêmica continuou sendo, por um lado, o conflito entre educação pública, gratuita, laica e de qualidade para todos e, por outro, a educação privada. Nesse cenário, ressurge o debate acerca da dualidade entre educação propedêutica e profissional 
A relação entre a educação profissional e a educação básica na CONAE $2010 \ldots$

(Frigotto, Ciavatta \& Ramos, 2005). Discute-se, então, no Projeto de LDB do deputado Otávio Elísio, a educação geral integrada à EP na perspectiva da politecnia, ${ }^{1}$ cujo significado não pode ser compreendido de forma literal, conforme ensina Saviani (2003, p. 140):

Politecnia, literalmente, significaria múltiplas técnicas, multiplicidade de técnicas, e daí o risco de se entender esse conceito como a totalidade das diferentes técnicas, fragmentadas, autonomamente consideradas. A proposta da profissionalização do ensino de segundo grau da Lei n. 5.692/ 71 (...) tendia a realizar um inventário das diferentes modalidades de trabalho (...). A escola de segundo grau teria a tarefa de formar profissionais nas diferentes especialidades requeridas pelo mercado de trabalho.

\section{Entretanto, continua o autor,}

A noção de politecnia não tem nada a ver com esse tipo de visão. Politecnia diz respeito ao domínio dos fundamentos científicos das diferentes técnicas que caracterizam o processo de trabalho produtivo moderno. Está relacionada aos fundamentos das diferentes modalidades de trabalho e tem como base determinados princípios, determinados fundamentos, que devem ser garantidos pela formação politécnica. Por quê? Supóe-se que, dominando esses fundamentos, esses princípios, o trabalhador está em condiçôes de desenvolver as diferentes modalidades de trabalho, com a compreensão do seu caráter, sua essência. Não se trata de um trabalhador adestrado para executar com perfeição determinada tarefa e que se encaixe no mercado de trabalho para desenvolver aquele tipo de habilidade. Diferentemente, trata-se de propiciar-lhe um desenvolvimento multilateral, um desenvolvimento que abarca todos os ângulos da prática produtiva, na medida em que ele domina aqueles princípios que estão na base da organização da produção moderna. (Idem, ibid.)

Essa era a proposta de médio e longo prazo a ser construída gradativamente, a utopia a ser alcançada. Nisso convergem educadores como Demerval Saviani, Gaudêncio Frigotto, Maria Ciavatta, Marise Ramos, Acácia Kuenzer, Domingos Lima Filho, entre outros. Assim, a escolha por uma profissão, em nível universitário ou não, poderia ocorrer após a conclusão da EB, a partir dos 18 anos de idade. Para alcançá-la, seria necessário que a sociedade brasileira a assumisse como indispensável, pressionando o Estado a tomar a decisão política de fazê-lo, o que demandaria esforço e tempo (talvez décadas!), com ações desenvolvidas a partir de planejamento que contemplasse, além da concepção e dos princípios 
norteadores, dimensôes como financiamento; colaboração entre os entes federados e as redes públicas; quadro de profissionais da educação e sua adequada formação inicial e continuada; e infraestrutura física, ou seja, um projeto societário e, em consequência, educacional, diferente do hegemônico.

Contudo, tal concepção perdeu-se gradativamente durante o processo que resultou na segunda LDB, seguida do Decreto n. 2.208/1997 que, a pretexto de regulamentar a primeira, separou obrigatoriamente $\mathrm{O}$ EM da EP, produzindo grandes prejuízos a ambos durante o período de sua vigência e, inclusive, após a sua revogação, uma vez que é difícil desconstruir todo o aparato ideológico que fez parte das reformas educacionais dos anos de 1990, ainda presente nas políticas atuais.

Para financiar essa reforma, o governo negociou empréstimo junto ao Banco Interamericano de Desenvolvimento (BID), materializado por meio do Programa de Expansão da Educação Profissional (PROEP).

Apesar da crítica que merecem os princípios da reforma, importa saber que ela e o PROEP foram coerentes com a lógica que os patrocinou. Vários aspectos demonstram isso. Merece ressaltar que os recursos desse Programa foram destinados a três segmentos: o público federal, o público estadual e o comunitário.

A definição do último segmento serviu como pretexto para a transferência de dinheiro público à iniciativa privada, que atuava ou pretendia atuar na EP. Dessa forma, montante significativo foi transferido a escolas desse segmento, muitas delas sem nenhum histórico de atuação na EP. Esse movimento implicou em resultados medíocres no que se refere aos cursos proporcionados à população e, também, na perda de recursos públicos, de maneira que até hoje várias escolas do segmento comunitário ainda não aprovaram suas contas em relação ao PROEP.

Destaca-se, ainda, a função do PROEP junto à rede federal de EP, no sentido de reestruturá-la desde o ponto de vista de suas ofertas educacionais, da gestão e das relações empresariais e comunitárias, na perspectiva de torná-la competitiva no mercado educacional, o que implicaria assumir a nova função de arrecadar a partir da prestação de serviços à comunidade, visando ao seu autofinanciamento parcial.

Ressalta-se, também, que os critérios de acessibilidade aos recursos do PROEP eram coerentes com a reforma. Assim, eram sumariamente descartadas as propostas que incluíam ações no âmbito do EM, o que 
A relação entre a educação profissional e a educação básica na CONAE $2010 \ldots$

era compatível com a separação EM/EP e com o afastamento definitivo dessa rede da EB.

Foi diante desse quadro que se chegou aos anos 2000, quando a conjuntura política permitiu retomar, a partir de 2003, a discussão acerca da relação da EP com a EB.

Educação profissional e ensino médio nos anos 2000: do Decreto n. 5.154/2004 ao novo PNE, passando pela CONAE

Ainda no final de 2002, no período de transição entre os governos FHC e Lula, retoma-se a discussão sobre a relação entre o EM e a EP no âmbito da equipe que elaborou a proposta educacional do novo governo. Em 2003, ocorreram seminários nacionais sobre o EM e sobre a EP, cujo cerne foi a relação entre eles. As discussões políticas e teóricas foram intensas e polêmicas, sendo que seu acúmulo se materializou no Decreto n. 5.154/2004, o qual aponta para a possibilidade de integração entre o EM e a EP, mas mantém as outras duas possibilidades de articulação previstas no Decreto n. 2.208/1997: as formas subsequente e concomitante. Essas múltiplas possibilidades constituem-se em bom indicador das mencionadas polêmicas.

Compreende-se que a forma subsequente - cursos técnicos de nível médio destinados a quem já concluiu o EM - justifica-se pelo fato de que há muitos jovens e adultos que concluíram o EM propedêutico de baixa qualidade e que não vão para o ES, nem têm condições de inserção em atividades complexas, entre as ocupações de nível médio. ${ }^{2}$ Assim, em razão dessa distorção, que é fruto da incapacidade do Estado brasileiro de garantir educação básica com qualidade para todos, os cursos técnicos subsequentes podem contribuir para melhorar as condiçóes de inserção social, política, cultural e econômica desses brasileiros.

Por sua vez, a forma concomitante - cursos técnicos destinados a quem está fazendo o ensino médio, mas com matrícula independente desse - representa, na prática, a permanência dos princípios oriundos do Decreto n. 2.208/1997, mesmo após a sua revogação. Em outras palavras, essa forma se encarregou de manter viva, no plano legal e prático, a dualidade estrutural entre EM e EP e foi fruto das disputas no âmbito do próprio governo de coalizão e da sociedade civil, em que forças importantes, notadamente aquelas vinculadas ao Sistema " $S$ ", pretendiam manter o rumo das reformas dos anos de 1990. 
De qualquer maneira, a possibilidade de integração entre EM e EP, constante no Decreto n. 5.154/2004, representa uma possibilidade de avanço na direção de construir um ensino médio igualitário para todos, pois, apesar de não se confundir com a politecnia, fundamenta-se em seus princípios e é exigência de uma sociedade na qual a elevada desigualdade socioeconômica obriga grande parte dos filhos das classes populares a buscar, bem antes dos 18 anos de idade, a inserção no mundo do trabalho, visando a complementar a renda familiar. No entanto, esta deve ser vista como uma solução transitória, pois é fundamental avançar na direção de construir uma sociedade na qual esses jovens das classes populares tenham o direito de escolher uma profissão a partir dos 18 anos de idade (como sempre tiveram os filhos das classes média-alta e alta). É também viável, porque "o ensino médio integrado ao ensino técnico, sob uma base unitária de formação geral, é uma condição necessária para se fazer a 'travessia' para uma nova realidade" (Frigotto, Ciavatta \& Ramos, 2005, p. 43).

Essa proposta fundamenta-se na integração entre trabalho, ciência, tecnologia e cultura, os quais também se integram a uma formação profissional específica. Por isso, sua denominação literal poderia ser EM integrado, integrado à EP. Tal proposta vem sendo implantada, ainda que timidamente, a partir de 2005, na rede federal de EP e em algumas redes estaduais. Não obstante, é preciso avançar também na direção do EM politécnico, ou seja, sem terminalidade em uma profissão específica EM integrado.

Essas duas perspectivas, EM integrado à EP e EM integrado, pelas razões já expostas, não se confundem entre si, mas partem de uma base unitária constituída pela concepção de formação humana integral baseada na integração entre trabalho, ciência, tecnologia e cultura, tendo como princípios fundamentais: homens e mulheres como seres histórico-sociais; trabalho como princípio educativo; a realidade concreta como uma totalidade.

Apesar das duas possibilidades serem compatíveis e, conceitual e legalmente, viáveis, o processo histórico é contraditório e construído a partir da atuação dos distintos sujeitos, classes sociais (ou fragmentos) e grupos de interesse e das correlações de forças entre eles. Assim, justamente quando o Decreto n. 5.154/2004 possibilitou a integração do EM aos cursos técnicos, a Secretaria de Educação Média e Tecnológica (sEmTec) foi dividida, criando-se a Secretaria da Educação Básica (sEB) 
A relação entre a educação profissional e a educação básica na CONAE $2010 \ldots$

e a Secretaria de Educação Profissional e Tecnológica (SETEC). Dessa forma, enquanto no plano legal e na produção teórica se avança para a integração, a estrutura aponta para a separação entre EB e EP.

Todas essas contradições e polêmicas foram objeto de discussão nas conferências nacionais realizadas no âmbito educacional nos últimos anos - i CONFETEC (2006), CONEb (2008) e CONAE (2010) -, e os documentos finais produzidos em cada uma delas são coerentes entre si no que se refere à relação entre EM e EP, pois apresentam contradições internas semelhantes. ${ }^{3}$

Nesse sentido e considerando que o novo PNE será construído a partir do resultado da CONAE, neste texto a análise recairá sobre o Documento Final da última e consistirá na busca por identificar convergências e/ou divergências entre este e a base unitária que sustenta as duas possibilidades de EM integrado, caracterizada, anteriormente, de forma breve, tendo como pressuposto que a materialização dessa base unitária contribuirá para o rompimento da dualidade estrutural entre EM e EP.

A relação entre o EM e a EP é tema recorrente nesse documento, principalmente nos Eixos III (Democratização do Acesso, Permanência e Sucesso Escolar) e VI (Justiça Social, Educação e Trabalho: Inclusão, Diversidade e Igualdade), mas também há referência no Eixo V (Financiamento da Educação e Controle Social). A primeira referência explícita a essa relação está no Eixo III, quando, ao se referir às bases para a democratização do acesso, da permanência e do sucesso escolar, em todos os níveis e modalidades de educação, no item "e" se propõe

e) A busca da ruptura do dualismo estrutural entre o ensino médio e a educação pública profissional (...), objetivando a ampliação das oportunidades educacionais, bem como a melhoria da qualidade de ensino para essa etapa da educação básica, inclusive na modalidade de educação de jovens e adultos. Nesse sentido, cabe compreender o ensino médio na concepção de escola unitária e de escola politécnica, para garantir a efetivação do ensino médio integrado, na sua perspectiva teórico-políticoideológica, conferindo materialidade à proposta de integração do Decreto n. 5.154, de 2004, como alternativa inicial, e a instituição plena da escola unitária, como meta (...). (Brasil, 2010, p. 69-70; destaques do original)

Neste item, o documento tem alguma coerência com a análise realizada neste texto, ou seja, aponta para o ensino médio politécnico 
como meta e para o ensino médio integrado como caminho para alcançá-lo. Ressalta-se como relevante a inclusão dos sujeitos da modalidade Educação de Jovens e Adultos (EJA) entre o público ao qual se destina o EM integrado.

Apesar disso, já neste item aparece uma marca importante da disputa em torno de distintos projetos societários e, em particular, educacionais. O leitor pode observar que o texto se refere à busca do rompimento do dualismo estrutural entre o ensino médio e a educação pública profissional. Isso pressupõe que a educação profissional também poderá continuar sendo oferecida pela iniciativa privada e que, nesse caso, com o respaldo da CONAE, não é necessário buscar o rompimento da dualidade estrutural entre EM e EP.

Um pouco mais adiante, no item "f" do mesmo Eixo III, começa a se intensificar o caráter ambíguo do documento, quando se propõe

f) A expansão de uma educação pública profissional de qualidade, entendida na perspectiva do trabalho como princípio educativo, com financiamento público permanente que atenda às demandas produtivas e sociais locais, regionais e nacionais, em consonância com a sustentabilidade socioambiental e com a inclusão social. É preciso que a educação profissional no País atenda de modo qualificado às demandas crescentes por formação de recursos humanos e difusão de conhecimentos científicos, e dê suporte aos arranjos produtivos locais e regionais, contribuindo com o desenvolvimento econômico-social (...). (Idem, ibid.; destaques do original)

Neste item, vêm à luz contradições importantes. O texto é iniciado por "expansão de uma educação pública profissional de qualidade, entendida na perspectiva do trabalho como princípio educativo", mas um pouco depois se afirma: "É preciso que a educação profissional no País atenda de modo qualificado às demandas crescentes por formação de recursos humanos e difusão de conhecimentos científicos, e dê suporte aos arranjos produtivos locais e regionais, contribuindo com o desenvolvimento econômico-social". Aqui há dois aspectos importantes a analisar. Em primeiro lugar, a busca pela qualidade restringe-se à oferta pública, conforme o trecho inicial em destaque. Isso seria o ideal, caso o Estado brasileiro assumisse a responsabilidade integral com a educação em geral e com a EP, em particular. Entretanto, na análise precedente já ficou evidenciada a diretriz de que deve continuar existindo oferta privada de EP. 
A relação entre a educação profissional e a educação básica na CONAE $2010 \ldots$

Desse modo, a análise combinada dos itens "e" e "f" permite concluir que continuará existindo oferta privada de EP e que, nesse setor, o Estado não buscará por sua qualidade, assim como poderá continuar havendo dualidade entre a EP e o EM.

Outro aspecto que merece destaque é o fato de que o primeiro trecho se refere à EP fundada no trabalho como princípio educativo, ao passo que, no segundo, esta é vinculada ao atendimento às demandas por formação de recursos humanos para dar suporte aos arranjos produtivos locais e regionais.

Ora, o conceito de trabalho como princípio educativo é radicalmente incompatível com a formação de "recursos humanos", noção proveniente da teoria do capital humano. Na verdade, o trabalho como princípio educativo é um dos princípios fundantes do EM integrado e da politecnia. Tal princípio permite a compreensão do significado econômico, social, histórico, político e cultural das ciências e das artes, o que implica considerar o trabalho em seus sentidos ontológico e histórico. Em sua dimensão ontológica, considerar o trabalho como princípio educativo é compreendê-lo como relação fundamental entre o homem e a natureza e, desse modo, central na produção da existência humana.

No EM integrado, profissionalizante ou não, o trabalho também é princípio educativo em seu sentido histórico, ao considerar as diversas formas e significados que este vem assumindo ao longo do tempo nas sociedades. Isso permite compreender que, no capitalismo, o trabalho "se transforma em trabalho assalariado ou fator econômico, (...) portanto, como categoria econômica e práxis produtiva que, baseadas em conhecimentos existentes, produzem novos conhecimentos" (Ramos, 2004, p. 8).

Ao considerar essas duas dimensões, compreende-se que o trabalho como princípio educativo não se restringe ao "aprender trabalhando" ou ao "trabalhar aprendendo", pois está relacionado com a contribuição da ação educativa para que os indivíduos/coletivos compreendam, enquanto vivenciam e constroem a própria formação, que é socialmente justo que todos trabalhem, porque esse é um direito de todos; mas, igualmente, é uma obrigação coletiva, porque é a partir da produção de todos que se produz e se transforma a existência humana e, nesse sentido, não é justo que muitos trabalhem para que poucos enriqueçam cada vez mais, enquanto outros empobrecem e vivem à margem; 
ou, pior ainda, que muitos não tenham sequer direito ao trabalho e que isso seja funcional aos interesses econômicos hegemônicos.

Desse modo, a formação humana baseada no trabalho como princípio educativo não pode ser confundida com a formação de recursos humanos para atender às demandas do mercado de trabalho.

Entretanto, é no Eixo vi que o Documento Final da CONAE é mais problemático no que se refere à relação entre o EM e a EP. Seu texto como um todo materializa, definitivamente, o caráter ambíguo com que são tratados os termos justiça social, educação, trabalho, inclusão, diversidade e igualdade. Estes, ao serem polissêmicos, têm seus significados dependentes da concepção de ser humano, de sociedade, de ciência, de tecnologia, de cultura, enfim, de mundo que o sustente, sendo que, nessa parte do documento da CONAE, essas concepçóes estão muito próximas ao pensamento neoliberal e, portanto, submetidas à lógica da adaptação à realidade hegemônica, que tem centralidade na dimensão econômica e, no mercado, o instrumento para fortalecê-la. Dessa forma, afasta-se da perspectiva transformadora da realidade, com centralidade no ser humano e em suas relaçôes com a natureza, por meio do trabalho.

Assim, ao se referir a "políticas públicas que concorram para a justiça social, educação e trabalho, considerando a inclusão, a diversidade e a igualdade" (Brasil, 2010, p. 129), o documento estabelece que tais políticas, no que se refere "à formação cidadã e profissional" (p. 147), devem:

a) Garantir a articulação entre formação cidadã e profissional, com enfoque no direito de acesso da adolescência e juventude ao ensino médio, tendo em vista a ampliação da etapa de escolarização obrigatória no Brasil, entendida como uma demanda da sociedade brasileira em um contexto social de transformações significativas e, ao mesmo tempo, de construção de direitos sociais e humanos.

b) Consolidar a expansão de uma educação profissional de qualidade, que atenda as demandas produtivas e sociais locais, regionais e nacionais, em consonância com a sustentabilidade socioambiental e com a inclusão social.

c) Construir uma educação profissional que atenda, de modo qualificado, as demandas crescentes por formação de recursos humanos e difusão de conhecimentos científicos, e dê suporte aos arranjos produtivos locais e regionais, contribuindo para o desenvolvimento econômico-social. 
A relação entre a educação profissional e a educação básica na CONAE $2010 \ldots$

d) Garantir que os diferentes formatos institucionais e os diferentes cursos e programas na área tenham forte inserção na pesquisa e na extensão, estimulando o desenvolvimento de soluçōes técnicas e tecnológicas e estendendo seus benefícios à comunidade.

e) Consolidar a oferta do nível médio integrado ao profissional, bem como a oferta de cursos superiores de tecnologia, bacharelado e licenciatura (...). (p. 147-148)

Como se vê, o documento utiliza vários termos sem deixar claro o significado. Por exemplo, quando trata de "formação cidadã e profissional": qual o significado de formação humana e de cidadania que está sendo adotado? Esta expressão é utilizada no sentido da formação humana integral e igualitária para todos e que integre trabalho, ciência, tecnologia e cultura como eixos estruturantes e indissociáveis, voltada para a cidadania plena e autônoma, ou trata de uma formação diferenciada em função da classe social (ou fração) a que cada indivíduo pertence, sendo voltada para a adaptação às exigências do mercado de trabalho, na qual a cidadania é restrita e reduzida apenas a direitos e deveres dentro de uma lógica pré-estabelecida?

Ao analisar o conteúdo dos itens "a" a "e", é possível identificar a racionalidade que os fundamenta. Assim, observa-se que em nenhum deles há referência ao acesso igualitário de todos à educação escolar, sequer em uma perspectiva de futuro. Ao contrário, no item "d" está colocado como pressuposto que devem existir "os diferentes formatos institucionais e os diferentes cursos e programas (...)”. No caso da EP técnica de nível médio, isso sinaliza no sentido de que não há opção preferencial pelo EM integrado à EP como base para o EM politécnico e igualitário, tratado no item "e" do Eixo III e já mencionado anteriormente; ou, dito de outra maneira, aponta na direção de que terão o mesmo grau de prioridade o integrado, o concomitante e o subsequente. Evidentemente, isso não contribui para o rompimento da dualidade estrutural entre EM e EP. Ao contrário, potencializa-a.

O item " $b$ " se refere a expandir "uma educação profissional de qualidade, que atenda às demandas produtivas e sociais locais, regionais e nacionais, em consonância com a sustentabilidade socioambiental e com a inclusão social". Entretanto, não se explica o significado de EP de qualidade, de sustentabilidade socioambiental ou de inclusão social. 
Por isso, é necessário ir ao item "c" para compreender o sentido do texto. Neste item, explicita-se o objetivo de construir uma EP que atenda "as demandas crescentes por formação de recursos humanos (...)", revelando que o sentido de "uma educação profissional de qualidade", tratado no item "b", está diretamente relacionado com a subordinação da formação humana à lógica do setor produtivo, ou seja, formar indivíduos que possam se adaptar às exigências do mercado de trabalho, ao invés de sujeitos que possam, de forma autônoma, analisar criticamente a realidade da sociedade e, em particular, do mundo do trabalho e posicionar-se diante dela de forma competente, técnica e politicamente, em função dos interesses e necessidades coletivas, assim como dos seus próprios interesses.

Uma vez compreendido o significado que o texto assume para a expressão EP de qualidade, pode-se inferir acerca da conotação dada às expressões formação cidadã, inclusão social, equidade e diversidade. As duas últimas não aparecem nos itens em discussão, mas estão presentes no título e em outras partes do Eixo VI e estreitamente relacionadas com as primeiras.

Nesse panorama, os conceitos de diversidade e de inclusão se coadunam com o de equidade. O binômio diversidade/inclusão, considerado desde essa perspectiva, se materializa na esfera educativa no sentido de contribuir para a reprodução das classes sociais pela via do sistema educacional. $\mathrm{O}$ conceito distorcido de diversidade é a justificativa encontrada para a inclusão dos distintos grupos sociais por meio de programas e projetos, cujos públicos destinatários são definidos em razão do estado de maior ou de menor miséria. Para Garcia (2006, p. 122), diante dessa realidade,

O conceito de cidadania, como aquela qualidade que distinguia todos os indivíduos que passavam pela escola pública, foi reelaborado nos moldes do novo capitalismo periférico, que admite um conceito de cidadania mitigada. O direito do cidadão passa a ser considerado em razão do estado de carência ou de necessidade.

Há muita ambiguidade e hibridismo porque essa racionalidade, não raras as vezes, se apropria de pressupostos que historicamente fizeram (e continuam fazendo) parte das lutas das classes populares na busca do acesso de todos à educação em todos os níveis. Afinal, quem discorda de que os jovens e adultos que ainda não sabem ler e escrever, 
que não concluíram o ensino fundamental ou o médio, necessitam de políticas educacionais específicas voltadas à garantia desses direitos sociais? Da mesma forma, como divergir da necessidade de políticas educacionais específicas a serem destinadas às populações do campo, às comunidades de pescadores artesanais, aos quilombolas, aos indígenas, às pessoas com deficiência, enfim, aos diversos grupos étnico-raciais minoritários?

O problema consiste em que, partindo dessa premissa, considerada correta, ao invés de políticas, são implementados programas e projetos, cujo fim é promover ações que, no lugar de contribuírem para o acesso à educação de qualidade, base para a construção da cidadania plena, autônoma e emancipada, consolidam-se como medidas de contenção social, materializadas por meio de açôes compensatórias que resultam na construção de uma cidadania aviltada, precarizada, mitigada - enfim, da formação de meios ou quase-cidadãos -, uma inclusão excludente (Garcia, 2006; Kuenzer, 2007).

Enfim, na racionalidade que se pode apreender da leitura dos itens "a" a "e", a formação humana está voltada para a adaptação dos sujeitos a uma realidade que é considerada estática. Isso fere outro dos princípios fundamentais da formação humana integral: homens e mulheres como seres histórico-sociais. Explica-se esse princípio partindo da compreensão de que os seres humanos são histórico-sociais, portanto, capazes de transformar a realidade, ou seja, o humano

(...) busca a autonomia, a auto-realização e a emancipação através de sua participação responsável e crítica nas esferas sócio-econômico-política. Isto consiste em perceber o homem como um ser capaz de colocar-se diante da realidade histórica para, entre outros aspectos, reagir à coerção da sociedade, questionar as pretensóes de validade e de normas sociais, construir uma unidade de interesses e descobrir novas estratégias de atuação solidária. (CEFET-RN, 1999, p. 47)

No texto citado, incorpora-se a dimensão cultural aos aspectos sociais, econômicos e políticos mencionados, uma vez que a cultura determina e é determinada por todos eles, constituindo-se como dimensão central na construção da identidade individual e dos grupos sociais, enquanto a falta de uma cultura própria representa uma ameaça constante à perda dessa identidade e, em consequência, da assunção de identidades subalternas em relação a outras culturas que se pretendem hegemônicas. 
Diante disso, a formação humana integral vai além de proporcionar o acesso aos conhecimentos científicos e tecnológicos produzidos e acumulados pela humanidade. Promove o pensamento crítico sobre os códigos de cultura manifestados pelos grupos sociais ao longo da história, como forma de compreender as concepções, problemas, crises e potencialidades de uma sociedade, e para que o sujeito, a partir daí, possa contribuir para a construção de novos padrões de produção de conhecimento, de ciência e de tecnologia, voltados para os interesses sociais e coletivos. Nesse contexto, o humano é capaz de se produzir e se modificar na sua relação com o trabalho, com os demais seres humanos e com a natureza, em um movimento dialético sujeito/objeto. Desde logo, formar recursos humanos para se adaptar às demandas do setor produtivo está muito distante da perspectiva da formação humana integral.

\section{Breves apontamentos à continuação do debate}

Para continuar o debate, importa ratificar a possibilidade concreta que tem a proposta de integração entre a EP e o EM, fundamentada nos princípios da politecnia, de contribuir para o rompimento da dualidade estrutural entre ambos, assim como para a qualificação social deles, conferindo-lhes maior sentido para adolescentes, jovens e adultos brasileiros, principalmente para os das classes populares.

Entretanto, a análise comparativa realizada entre essa concepção de integração e o que aponta o Documento Final da CONAE, especialmente em seu Eixo VI, desvela que tal documento não traz elementos significativos para que o novo PNE possa contribuir para materializar tal integração.

Contrariamente, a análise permitiu identificar contradições e hibridismos no documento. Assim sendo, reitera-se a importância de compreender que as expressões justiça social, educação e trabalho: inclusão, diversidade e igualdade não carregam significado único. Ao contrário, são extremamente polissêmicas.

Essa compreensão é básica no momento de construir o novo PNE, pois, ao elaborá-lo segundo o sentido dado a esses termos no Eixo VI, se potencializará a formação de sujeitos autômatos, verdadeiras peças que deverão se encaixar nas engrenagens que estão em funcionamento, no sentido de atender às exigências dos que detêm o poder hegemônico, para 
A relação entre a educação profissional e a educação básica na CONAE $2010 \ldots$

os quais os seres humanos das classes populares são apenas mão de obra, força de trabalho ou recursos humanos.

De outro modo, a referência pode ser "A busca da ruptura do dualismo estrutural entre o ensino médio e a educação pública profissional (...)", visando a "garantir a efetivação do ensino médio integrado, na sua perspectiva teórico-político-ideológica, conferindo materialidade à proposta de integração do Decreto $n$. 5.154, de 2004, como alternativa inicial, e a instituição plena da escola unitária, como meta”, constante no Eixo III (p. 69-70).

Tal perspectiva potencializará a formação de sujeitos autônomos, competentes tecnicamente e comprometidos politicamente com mudanças profundas no funcionamento das engrenagens, visando à construção de uma sociedade na qual possa haver igualdade substantiva entre os seres humanos, estancando assim a produção, em larga escala, da deterioração do planeta, da concentração de riquezas, para uma pequena minoria, e do empobrecimento (ou a sua manutenção) da grande maioria dos seres humanos.

Finalmente, também se reitera a importância de estar atentos ao fato de que, muitas vezes, dada a polissemia dos termos envolvidos, a linha que demarca as concepções discutidas ao longo deste texto é propositalmente obscurecida sob denominaçóes como iniciativas de responsabilidade social ou politicamente corretas. Dessa forma, muitas ações que se apresentam como voltadas ao atendimento dos interesses das classes populares, na verdade, ao serem submetidas a uma análise rigorosa, revelam-se contrárias a esses interesses. É o que Accino (2000) denomina de lobo vestido em pele de cordeiro. Tenha-se, pois, cuidado redobrado com os cordeiros.

Recebido e aprovado em agosto de 2010.

\section{Notas}

1. Para Saviani (2003), educação tecnológica é o termo que melhor traduz o significado marxista de politecnia. Dessa forma, serão utilizados como expressões sinônimas. Entretanto, ele adverte que é preciso ter cuidado com o uso do termo educação tecnológica, em função da apropriação que a concepção burguesa da educação fez do termo tecnologia.

2. A taxa de escolarização bruta na educação superior brasileira é de cerca de $20 \%$ e a líquida é de $13 \%$. Sendo assim, pelo menos $80 \%$ da população vivem a fase adulta com uma 
escolarização formal que não ultrapassa o ensino médio, o qual, majoritariamente, não discute as questôes inerentes ao mundo trabalho. Nessa perspectiva, essa parcela significativa da população está fadada a sobreviver por meio de atividades periféricas da sociedade. Nesse sentido, os cursos técnicos subsequentes constituem-se em uma alternativa válida.

3. Além das contradições discutidas, outras também contribuem para a manutenção ou até para a ampliação da dualidade estrutural entre EM e EP, entre elas: o projeto EM inovador, lançado pelo MEC em 2008, e a discussão no âmbito do CNE sobre novas diretrizes para a EP, cuja proposta retoma os princípios da reforma da EP dos anos de 1990.

\section{Referências}

ACCINO, J.A. El silencio de los corderos sobre las tecnologías de la información y la educación. Heuresis, Málaga, v. 2, n. 3, 1999. Disponível em: <http://www2.uca.es/HEURESIS/heuresis99/v2n3.htm>. Acesso em: 6 mar. 2000.

CENTRO FEDERAL DE EDUCAÇÃO TECNOLÓGICA DO RIO GRANDE DO NORTE. Proposta de reestruturação curricular. Natal: CEFET-RN, 1999.

CONFERÊNCIA NACIONAL DE EDUCAÇÃO (CONAE), 2010, Brasília, DF. Construindo o Sistema Nacional Articulado de Educação: o Plano Nacional de Educação, diretrizes e estratégias; Documento Final. Brasília, DF: MEC, 2010. Disponível em: <http://Conae.mec.gov.br/ images/stories/pdf/pdf/doc_base_documento_final.pdf>. Acesso em: 7 jun. 2010.

FREITAG, B. Escola, Estado e sociedade. São Paulo: Moraes, 2000.

FRIGOTTO, G.; CIAVATTA, M.; RAMOS, M. (Org.). Ensino médio integrado: concepção e contradições. São Paulo: Cortez, 2005.

GARCIA, W. Tecnocratas, educadores e os dilemas da gestão. In: FERreirA, N.S.C. (Org.). Gestão da educação: impasses, perspectivas e compromissos. São Paulo: Cortez, 2006. p. 113-128.

GERMANO, J.W. Estado militar e educação no Brasil. 4. ed. São Paulo: Cortez, 2005.

KUENZER, A.Z. Ensino médio e profissional: as políticas do Estado neoliberal. São Paulo: Cortez, 1997. 104p. 
KUENZER, A.Z. Da dualidade assumida à dualidade negada: o discurso da flexibilização justifica a inclusão excludente. Educação \& Sociedade, Campinas, v. 28, n. 100, p. 1153-1178, out. 2007. Disponível em: <http://www.scielo.br/scielo.php?script=sci_arttext \&pid=S0101$73302007000300024 \& \operatorname{lng}=$ en $\& n r m=$ iso $>$. Acesso em: $1^{\circ}$ set. 2010.

RAMOS, M.N. O projeto unitário de ensino médio sob os princípios do trabalho, da ciência e da cultura. In: Frigotto, G.; Ciavatta, M. (Org.). Ensino médio: ciência, cultura e trabalho. Brasília, DF: MEc/ SEMTEC, 2004.

SAVIANI, D. O choque teórico da politecnia. Educação, Trabalho e Saúde, Rio de Janeiro, v. 1, n. 1, p. 131-152, mar. 2003. 